\title{
Inflammatory bowel disease in Chinese children: A retrospective analysis of 49 cases
}

\author{
YING ZHOU and YING HUANG \\ Department of Gastroenterology, Children's Hospital of Fudan University, Shanghai 201102, P.R. China
}

Received July 6, 2015; Accepted August 25, 2016

DOI: $10.3892 /$ etm.2016.3756

\begin{abstract}
To present study reports the clinical characteristics, diagnosis and management of pediatric patients with inflammatory bowel disease (IBD) in China. Clinical records of 49 pediatric patients with IBD at Fudan University Children's Hospital (Shanghai, China) between July 2001 and May 2012 were reviewed. Of 49 patients (30 males and 19 females), 8 patients had ulcerative colitis (UC) and 41 patients had Crohn's disease (CD). The mean age was 10.4 years in patients with UC and 10.1 years in patients with $\mathrm{CD}$. The percentages of patients with UC with abdominal pain, diarrhea or rectal bleeding were $62.5,100$ and $87.5 \%$, respectively, and that of CD patients were $75.6,61$ and $39 \%$, respectively. Patients with UC were underweight (37.5\%), and had oral ulcers $(12.5 \%)$ and arthritis (12.5\%), and patients with CD were underweight (34.1\%), and had oral ulcers (26.8\%), anal fistulas (22\%) and arthritis (19.5\%). Patients with CD had a higher proportion of immunoglobulin G, C-reactive protein and erythrocyte sedimentation rate compared with patients with UC. Histologic lesions of patients with UC were primarily located in the sigmoid colon $(75 \%)$, transverse colon $(50 \%)$ or pan-colon $(50 \%)$, and in patients with CD they were located in the distal ileum $(51.2 \%)$, ileocecum $(58.5 \%)$ or upper gastrointestinal tract $(41.5 \%)$. All patients underwent colonoscopies and 13 underwent double-balloon enteroscopies. Standard treatment for IBD, including corticosteroids, 5-aminosalicylate, and immunosuppressants (6-mercaptopurine and azathioprine), were administered to all patients. In addition 3 patients were treated with infliximab and 10 patients were treated with thalidomide. Comprehensive assessment of clinical, laboratory, endoscopic, and pathohistological data will benefit the timely diagnosis of IBD.
\end{abstract}

Correspondence to: Dr Ying Huang, Department of Gastroenterology, Children's Hospital of Fudan University, 399 Wan-Yuan Road, Shanghai 201102, P.R. China

E-mail: yhuang815@163.com

Key words: child, inflammatory bowel disease, infliximab, thalidomide

\section{Introduction}

Inflammatory bowel disease (IBD) is a chronic non-specific disorder of unknown etiology, and includes ulcerative colitis (UC), Crohn's disease (CD) and indeterminate colitis. Recent epidemiological studies indicate a rising incidence of IBD in adults and children $(1,2)$. However, the majority of published studies have focused on adults, and delayed diagnosis is common in children worldwide $(3,4)$. Conventional diagnostic methods may fail to identify a subset of patients with small bowel involvement. Double-balloon enteroscopy (DBE), a technique for deep diagnostics and a therapeutic for small bowel endoscopy, was described in 2001 by Yamamoto et al (5). DBE is an established modality of investigation in adults, but it has not been used widely in children and is available in few pediatric centers in China (6).

The clinical course of CD may include various intra- and extra-intestinal complications, and its serious and chronic nature has shown to adversely affect patients' quality of life (7). Approximately $10 \%$ of patients with UC present with severe clinical symptoms requiring hospitalization and treatment with intravenous corticosteroids (8). Infliximab is a chimeric immunoglobulin G1 monoclonal antibody, which binds to tumor necrosis factor- $\alpha$ with high affinity and specificity, and has been proved effective in adults with CD who had an inadequate response to conventional therapy (9), as well as in patients with UC (10). Thalidomide has been intensified in recent years as researchers have identified and clarified its immunomodulatory and anti-angiogenic properties $(11,12)$. Based on the apparent anti-TNF- $\alpha$ properties of thalidomide, a previous study performed by the authors of the present study used it successfully to treat a 12-year-old boy with refractory CD and concomitant tuberculosis (TB) infection in 2006 (13). This experience resulted in the authors of the current study initiating a thalidomide treatment trial for refractory cases of CD in 10 children.

Few published studies have reviewed IBD in Chinese children (14). A steadily increasing trend of 0-14-year-old childhood IBD in Shanghai, rising from 0 in 2000 to 6.051 in 2010 per $10^{6}$ populations for the year-specific incidence rate, has been found (14). However, few studies have reported the use of DBE and thalidomide in children with refractory IBD. The present study is a retrospective, multicenter hospital-based study that was performed over an 11-year period. The data of 49 pediatric patients diagnosed with IBD at Fudan University 
Children's Hospital (Shanghia, China), and the preliminary experience in the diagnosis and treatment of IBD in these children, are reviewed.

\section{Materials and methods}

Patients and study design. Between July 2001 and May 2012, 49 pediatric patients (30 males and 19 females) were reviewed at Fudan University Children's Hospital. The diagnosis of $\mathrm{UC}$ or CD was appropriately evaluated by a physician. All cases met the criteria established by the Society of Pediatrics of China, 2010 (15). Every child suspected of UC or $\mathrm{CD}$ underwent a complete diagnostic program, consisting of colonoscopy with ileal intubation, upper gastrointestinal endoscopy and radiologic contrast imaging of the small bowel. In addition, DBE was performed in suspected cases with small intestine involvement. Multiple biopsies from all segments of the gastrointestinal tract (including pathological and normal tissues) were required for a complete histologic evaluation. Formalin-fixed, paraffin-embedded sections $(3-\mu \mathrm{m})$ were stained with hematoxylin-eosin, then examined under a BX51 light microscope (Olympus Corporation, Tokyo, Japan). The data of 49 patients with IBD included general information, clinical presentation and symptoms, laboratory findings and therapeutic management.

Physical examinations, laboratory analyses, and pediatric CD activity index (PCDAI) scoring (16) were performed of the 49 patients at baseline, weeks 2,8 and 12 , and every 3 months thereafter, until the patients reached 18 years of age. Endoscopies were repeated at 6 months after thalidomide administration. The patients were monitored intensively for any side effects during the follow-up period.

Ethics. The present study was approved by the Institutional Ethics Committee of the Children's Hospital of Fudan University, and informed consent was obtained from the patients or guardians of the patients included in the study.

\section{Results}

Patient characteristics. Eight (16.3\%) of the 49 patients with partial enteral nutrition had UC ( 3 males and 5 females; age, 6-15 years; 2 mild, 4 moderate and 2 severe cases) and 41 (83.7\%) had CD (27 males and 14 females; age, 1-17 years; 21 mild and 20 moderate/severe cases). The UC:CD ratio was 1:5.1, and the male:female ratio was 1:0.63. The patients' age distribution is presented in Table I. The mean age at diagnosis was 10.4 years (range, 6.2-14.9 years) in patients with $\mathrm{UC}$ and 10.1 years (range, 1.5-16.9 years) in patients with $\mathrm{CD}$.

Clinical manifestations. The mean interval between presentation and diagnosis was 10.2 months (range, 0.5-24 months) for patients with UC and 9.7 months (range, 0.5 months-5 years) for patients with $\mathrm{CD}$. The clinical manifestations of the 49 patients with UC or CD are presented in Table II. In this study, the common manifestations primarily included abdominal pain, diarrhea and rectal bleeding, which are typical symptoms of IBD (17). The percent of patients with UC with abdominal pain, diarrhea or rectal bleeding were $62.5,100$ and $87.5 \%$, respectively, and the percent of patients
Table I. Age distribution of pediatric patients with inflammatory bowel disease.

\begin{tabular}{|c|c|c|c|c|}
\hline \multirow[b]{2}{*}{ Disease } & \multicolumn{4}{|c|}{ Age (years) } \\
\hline & $<3$ & $3-6$ & $7-12$ & $13-17$ \\
\hline $\mathrm{UC}(\%)$ & $0(0)$ & $0(0)$ & $6(75)$ & $2(25)$ \\
\hline $\mathrm{CD}(\%)$ & $5(12.2)$ & $2(4.9)$ & $14(34.1)$ & $20(48.8)$ \\
\hline
\end{tabular}

UC, ulcerative colitis; $\mathrm{CD}$, Crohn's disease.

Table II. Primary manifestations of inflammatory bowel disease in 49 pediatric patients.

\begin{tabular}{llc}
\hline Manifestations & $\mathrm{UC}, \mathrm{n}=8$ & $\mathrm{CD}, \mathrm{n}=41$ \\
\hline $\begin{array}{l}\text { Common manifestations, } \mathrm{n}(\%) \\
\text { Abdominal pain }\end{array}$ & $5(62.5)$ & $31(75.6)$ \\
Diarrhea & $8(100)$ & $25(61)$ \\
Rectal bleeding & $7(87.5)$ & $16(39)$ \\
Extraintestinal manifestations, $\mathrm{n}(\%)$ & & \\
Underweight & $3(37.5)$ & $14(34.1)$ \\
Abdominal mass & $0(0)$ & $2(4.9)$ \\
Oral ulcer & $1(12.5)$ & $11(26.8)$ \\
Arthritis & $1(12.5)$ & $8(19.5)$ \\
Anal fistula & $0(0)$ & $9(22)$ \\
Intestinal perforation & $0(0)$ & $0(0)$ \\
Erythra & $0(0)$ & $6(14.6)$ \\
\hline
\end{tabular}

UC, ulcerative colitis; CD, Crohn's disease.

with CD were 75.6, 61 and 39\%, respectively (Table II). The most common manifestation was diarrhea in patients with $\mathrm{UC}$ and abdominal pain in patients with CD. Extra-intestinal manifestations (EIM) were also documented, including being underweight, and having abdominal masses, oral ulcers, arthritis, anal fistulas, intestinal perforation and erythra (Table II). The EIM in patients with UC were being underweight $(37.5 \%)$, and having oral ulcers $(12.5 \%)$ and arthritis (12.5\%), and the EIM in patients with CD were being underweight (34.1\%), and having oral ulcers (26.8\%), anal fistulas (22\%), arthritis (19.5\%), erythra (14.6\%) and abdominal masses (4.9\%) (Table II). At least one EIM was found in 25\% of patients with UC and $73.2 \%$ of patients with CD. There were $26.5 \%$ (13/49) of cases in the present study who had been misdiagnosed as dysentery.

Laboratory findings. Routine blood and other laboratory test results were obtained. The percent of patients with UC with immunoglobulin G (>12 g/l), C-reactive protein $(>20 \mathrm{mg} / \mathrm{l})$ or erythrocyte sedimentation rate $(>25 \mathrm{~mm} / \mathrm{h})$ were 25,25 and $50 \%$, respectively, and these percentages in patients with UC were $51.2,68.3$ and $70.7 \%$, respectively (Table III). In addition, patients with $\mathrm{CD}$ had a higher proportion of cases with increased levels of immunoglobulin G, C-reactive protein and 
Table III. Laboratory findings of pediatric patients with inflammatory bowel disease.

\begin{tabular}{llc}
\hline Parameter & $\begin{array}{c}\mathrm{UC} \\
\mathrm{n}=8\end{array}$ & $\begin{array}{c}\mathrm{CD} \\
\mathrm{n}=41\end{array}$ \\
\hline White blood cells $>15 \times 10^{9} / \mathrm{l}, \mathrm{n}(\%)$ & $2(25)$ & $6(14.6)$ \\
Hemoglobin $<90 \mathrm{~g} / \mathrm{l}, \mathrm{n}(\%)$ & $1(12.5)$ & $5(12.2)$ \\
Platelets $>400 \times 10^{9} / \mathrm{l}, \mathrm{n}(\%)$ & $1(12.5)$ & $18(43.9)$ \\
Albumin $<35 \mathrm{~g} / \mathrm{l}, \mathrm{n}(\%)$ & $2(25)$ & $18(43.9)$ \\
$\begin{array}{l}\text { Immunoglobulin } \mathrm{G}>12 \mathrm{~g} / \mathrm{l}, \mathrm{n}(\%) \\
\text { C-reactive protein }>20 \mathrm{mg} / \mathrm{l}, \mathrm{n}(\%)\end{array}$ & $2(25)$ & $21(51.2)$ \\
$\begin{array}{l}\text { Erythrocyte sedimentation } \\
\text { rate }>25 \mathrm{~mm} / \mathrm{h}, \mathrm{n}(\%)\end{array}$ & $4(50)$ & $28(68.3)$ \\
\hline
\end{tabular}

UC, ulcerative colitis; CD, Crohn's disease.

erythrocyte sedimentation rate compared with patients with UC.

Endoscopic and pathohistological examination. Colonoscopy was performed in all cases and gastroscopy was performed in 27 cases. DBE was performed in 13 cases. Six of these patients had both colon and small intestinal involvement, and one case involved only the small intestine. The histologic lesions of patients with UC were primarily located in the sigmoid colon (75\%), transverse colon $(50 \%)$ or pan-colon $(50 \%)$, and the histologic lesions in patients with CD were primarily located in the distal ileum $(51.2 \%)$, ileocecum $(58.5 \%)$ or upper gastrointestinal tract (41.5\%) (Table IV). Analysis of the number and location of lesions revealed that more than two locations were involved in $70.7 \%$ (29/41) of patients with CD.

In patients with UC, histological findings identified inflammatory cell infiltration and lymph follicle formation. A crypt abscess was identified in one patient with UC. Lymphocyte and plasmocyte aggregation were observed in all patients with CD. The characteristic histological finding of non-caseating granuloma was seen in $29.2 \%$ (12/41) cases of CD.

Treatment. The goals of IBD treatment were to induce and maintain the remission of mucosal inflammation and other clinical symptoms, and to reduce the rate of growth retardation. The standard treatment for IBD was administered to all patients, including corticosteroids such as prednisone [5 mg per tablet; Actavis (Foshan) Pharmaceutical Co., Ltd., Foshan, Guangdong, China] at an initial dose of $2 \mathrm{mg} / \mathrm{kg}$ per day and adjusted according to patient's condition, 5-aminosalicylate (500 mg per bag; Shanghai Ethypharm Pharmaceutical Co., Ltd., Shanghai, China) at a dose of 50-80 mg/kg per day, immunosuppressants such as 6-mercaptopurine (50 mg per tablet; Zhejiang Hisun Pharmaceutical Co., Ltd., Taizhou, China) and azathioprine (AZA; 50 mg per tablet; Beijing Jialin Pharmaceutical Co., Ltd., Beijing, China) according to the patient's condition, as well as nutritional support. The majority of the patients who received the standard treatment for IBD responded well.

Two patients (one with UC, one with CD) with moderate-severe active IBD were administered infliximab (100 mg per branch; Parkedale Pharmaceuticals, Inc.,
Table IV. Distribution of histologic lesions in 49 pediatric patients with inflammatory bowel disease.

\begin{tabular}{llr}
\hline Lesion location & $\begin{array}{c}\mathrm{UC} \\
(\mathrm{n}=8)\end{array}$ & \multicolumn{1}{c}{$\begin{array}{c}\mathrm{CD} \\
(\mathrm{n}=41)\end{array}$} \\
\hline Rectum, n (\%) & $2(25)$ & $7(17.1)$ \\
Sigmoid colon, $\mathrm{n}(\%)$ & $6(75)$ & $9(22.0)$ \\
Descending colon, $\mathrm{n}(\%)$ & $3(37.5)$ & $8(19.5)$ \\
Transverse colon, n (\%) & $4(50)$ & $14(34.1)$ \\
Ascending colon, $\mathrm{n}(\%)$ & $1(12.5)$ & $11(26.8)$ \\
Pan-colon, $\mathrm{n}(\%)$ & $4(50)$ & $10(24.4)$ \\
Ileocecum, n $(\%)$ & $3(37.5)$ & $24(58.5)$ \\
Distal ileum, n $(\%)$ & $0(0)$ & $21(51.2)$ \\
Ileum, n $(\%)$ & $0(0)$ & $6(14.6)$ \\
Upper gastrointestinal tract, $\mathrm{n}(\%)$ & $0(0)$ & $17(41.5)$ \\
\hline
\end{tabular}

UC, ulcerative colitis; CD, Crohn's disease.

Rochester, Minnesota, USA) a dose of $5 \mathrm{mg} / \mathrm{kg}$ per day in weeks 0,2 and 6 and once in week 8 because oral glucocorticoids and immunosuppressants failed. In addition, one patient with CD and arthritis received infliximab treatment. All patients showed improvement in symptoms after the first infliximab infusion $(5 \mathrm{mg} / \mathrm{kg})$. No side effects following treatment were observed during the follow-up period.

Ten patients received thalidomide treatment $(25 \mathrm{mg}$ per tablet; Changzhou Pharmaceutical Co., Ltd., Changzhou, China) at an initial dose of $2 \mathrm{mg} / \mathrm{kg}$ per day and adjusted according to patient condition. Among these patients, seven with refractory $\mathrm{CD}$, which was defined as standard induction therapy with high-dose intravenous steroids, failed to induce remission either at diagnosis or during subsequent relapse; one developed a simultaneous TB infection and another two developed a suspected TB infection). Thalidomide was administered at an initial dose of $2.0 \mathrm{mg} / \mathrm{kg} / \mathrm{day}$, then increased to 2.5-3.0 mg/kg/day or decreased to $1.5 \mathrm{mg} / \mathrm{kg} / \mathrm{day}$, depending on each patient's response to drug. Six of the ten patients completed all follow-up assessments (13). After 3 months of thalidomide treatment, all patients achieved complete clinical remission with significant improvement of laboratory data, showed good tolerance of the drug, and then stopped steroid use. The endoscopic findings revealed marked improvement (Fig. 1). The remaining four patients who received thalidomide were still being followed-up at the time of manuscript submission, but their clinical symptoms and endoscopic characteristics improved in response to the treatment.

\section{Discussion}

Epidemiological studies have identified that the incidence of IBD has markedly increased during the past several decades (18). The onset of IBD within the first year of life has been documented in $1 \%$ of pediatric patients (19). In the patient sample in the present study, CD was more common compared with UC and showed a male preponderance; these findings are in agreement with previously published results (5). In a retrospective Chinese study, 82 patients with $C D$ and 71 patients 


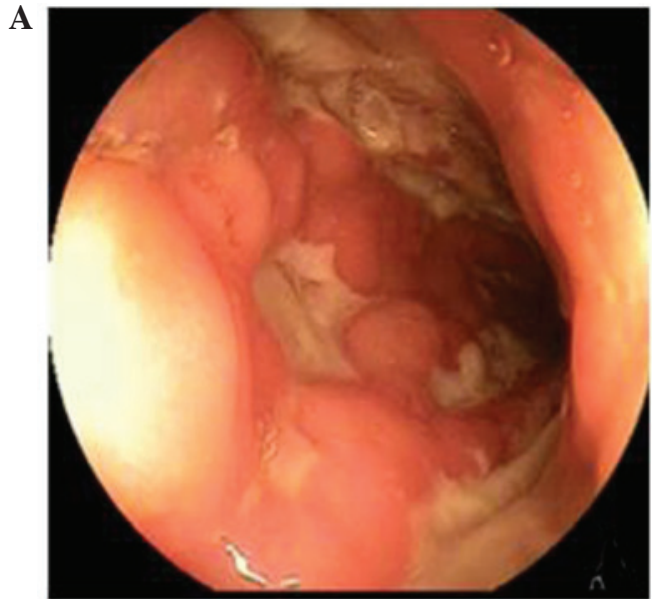

C

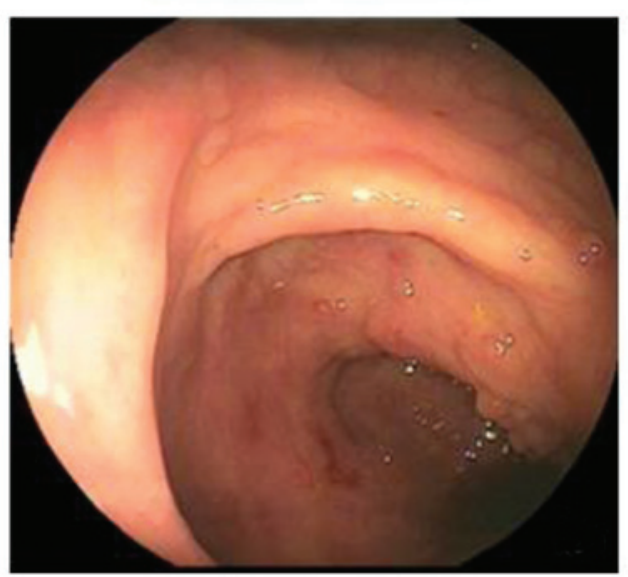

B

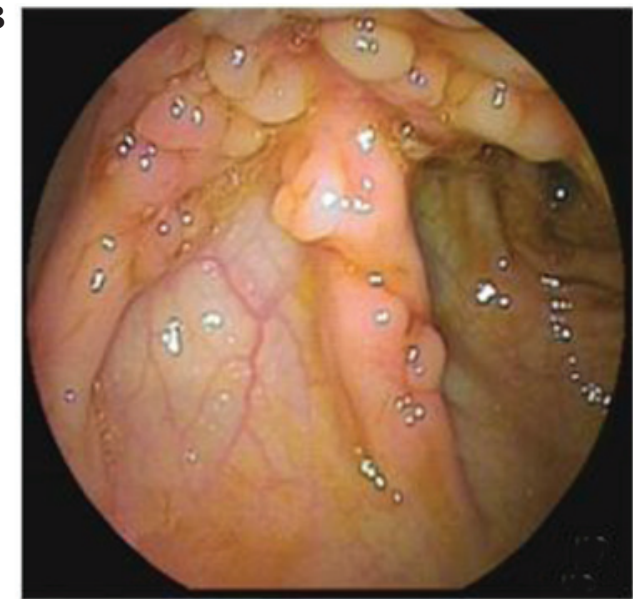

D

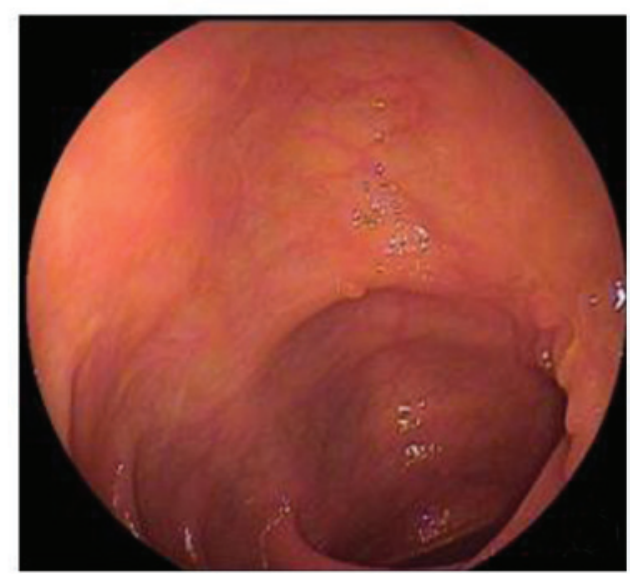

Figure 1. Endoscopic views of two patients (A and B) prior to treatment and $(\mathrm{C}$ and $\mathrm{D}) 6$ months after treatment with thalidomide.

with UC were reported with a male predominance (14). One larger study from the Japanese nationwide registry reported that between 2003 and 2006, newly registered patients, who were aged $\leq 16$ years, included 311 cases of $\mathrm{CD}(10.6 \%)$ and 880 cases of UC (5.9\%) (20). The authors of the present study purposed that the variances between studies were due to subjects being obtained from different regions and sample size.

In a study of children in France, the mean interval between presentation and diagnosis 2 months for UC and 4 months for CD (21). In the present study group, the mean intervals were longer; 10.2 months for UC and 9.7 months for CD, and 13 cases $(13 / 49,26.5 \%)$ were initially misdiagnosed as dysentery, which manifested diarrhea, mucous bloody stool, positive occult blood test and effective antibacterial treatment. As a result, these cases experienced delayed final diagnosis. Children with diarrhea, abdominal pain and blood in stool can often be mistakenly diagnosed with infectious diarrhea, which may lead to a delay in the true diagnosis. In pediatric IBD, growth failure may present in affected children before digestive symptoms develop (22). Two of the patients in the present study exhibited growth retardation; they visited their physicians because of microplasia without digestive symptoms, which did not develop until 1-2 years later.

In the current study, the most common manifestation was diarrhea in patients with UC and abdominal pain in patients with CD. The EIM for patients with UC and CD were being underweight, and having oral ulcers and arthritis. Diarrhea, abdominal pain, being underweight, oral ulcers and arthritis are symptoms of IBD (23-25). Patients with CD presented a higher proportion of immunoglobulin $\mathrm{G}, \mathrm{C}$-reactive protein and erythrocyte sedimentation rate compared with patients with UC. The results were consisted with the work of Vermerire et al (17), who determined that C-reactive protein was a marker to differentiate IBD (17). In addition, it has been determined that immunoglobulin $\mathrm{G}$ and erythrocyte sedimentation rates are closely associated with the development of IBD $(26,27)$.

$\mathrm{CD}$ is a chronic transmural IBD that may involve any part of the alimentary tract. The incidence rate of CD involving the esophagus, stomach and duodenum was identified as $63 \%$ $(17 / 27)$ in the present study, which is similar to the results in the study by Castellaneta et al (28). Castellaneta et al (28) suggested that multiple biopsies should be performed in children with suspected IBD who cannot be diagnosed enteroscopically, even in the absence of upper gastrointestinal symptoms. The majority of patients with $\mathrm{CD}$ in the present study had more than two lesions, and the lesions were more extensive compared with those in adults (29). Conventional diagnostic studies may fail to identify a subset of patients with small bowel involvement. In the current study, 13 patients underwent DBE with an anal approach. Six of these patients had colonic and small intestinal involvement, and one case involved only the small intestine. DBE has been proved to be a useful diagnostic tool for the evaluation of small bowel lesions in patients with CD (30), and can enable the appropriate 
adjustment of treatment to achieve clinical improvement. The significance of this finding is emphasized by the significant and sustained clinical improvement in the majority of patients following the adjustment of therapy (30-32).

The present study identified one crypt abscess among the patients with UC. Similar to other studies, pathohistological examination revealed markedly less obvious evidence of disease in children compared with adults $(33,34)$. Studies in adults have reported pathological changes in $\mathrm{CD}$, including crack ulcers and epithelioid granuloma in submucosa and subserous layer, in $70-75 \%$ of adults (35). The current study observed non-caseating granuloma in only 12 patients in the study sample; the low incidence rate may be due to the restricted dimensions and depth of the biopsies performed.

Infliximab, a TNF- $\alpha$ antibody, was administered to three patients, whose symptoms were improved after treatment. A number of studies have confirmed that infliximab is safe and effective in the treatment of IBD in children $(36,37)$. In China, infliximab is mostly used in patients with refractory IBD. Further follow-up studies should be conducted to evaluate the long-term efficacy and safety of infliximab therapy. In addition, infliximab is useful for relieving the EIM of IBD, such as pyoderma gangrenosum, angiitis, arthritis, nodular erythema and uveitis. However, infliximab should not be administered to patients with sepsis, TB infection and/or intestinal tract stenosis. In comparison with conventional 'step-up' therapy, 'top-down' or early aggressive treatment (infliximab + AZA) show superiority in mucosal healing, rapid remission and remission rates (38).

Biological treatment is expensive and cannot be used in patients with TB infection, which remains common in China. The treatment of patients with simultaneous CD and TB infection is challenging because the administration of steroids or immunosuppressants may result in the reactivation of latent TB or exacerbate the infection. In China, few patients can afford the high cost of infliximab. The development of novel treatment modalities to help this group of patients is urgently needed.

In agreement with the results of other studies $(39,40)$, thalidomide (13) treatment improved the symptoms of 10 patients with refractory CD in the present study. Studies have demonstrated that thalidomide therapy can enhance the response to anti-TB drugs $(41,42)$. In the current study, it was observed that thalidomide was a good therapeutic option for patients with IBD and concomitant or suspected TB. In addition, positive responses, including weight gain, improved endoscopic findings and improved PCDAI scores, were observed at 2-3 weeks after the initiation of thalidomide treatment in the present study, which is an improvement compared with patients who received steroids only. The side effects of thalidomide, including peripheral neuropathy, drowsiness, fatigue, constipation, xerosis cutis and granulocytopenia, were tolerable for patients during the follow-up period in the current study, and no severe neurotoxicity was observed. Due to the irreversible neurotoxicity with a dose- and time-dependent manner, the clinical application of thalidomide treatment is limited and nerve conduction velocity tests should be performed during follow-up examinations (43).

The present study was limited by a number of factors. Firstly, the sample size of patients with UC was too small to compare the difference between patients with UC and CD. Hence, a multicenter study with a large sample size is required. Secondly, a small number of patients in the present study received thalidomide. The long-term efficacy and safety of thalidomide should be further evaluated in a large-scale randomized controlled trial.

In conclusion, in the patient sample in the current study, $\mathrm{CD}$ was more common than UC and showed a male preponderance. The mean age at diagnosis was 10.4 years in patients with UC and 10.1 years in patients with CD. The most common manifestation was diarrhea in patients with UC and abdominal pain in patients with CD. The EIM for patients with UC and CD were being underweight, and oral ulcers and arthritis. Patients with CD presented a higher proportion of immunoglobulin G, C-reactive protein and erythrocyte sedimentation rate compared with patients with UC. In addition, the administration of infliximab and thalidomide achieved remission in refractory cases and the tolerance was acceptable.

\section{Acknowledgements}

The authors thank Professor Huang's team members (Department of Gastroenterology, Children's Hospital of Fudan University, Shanghai, China) for their helpful discussion and critical reading of the manuscript.

\section{References}

1. Shin DH, Sinn DH, Kim YH, Kim JY, Chang DK, Kim EJ, Ryu HY, Song HU, Kim IY, Kim do H, et al: Increasing incidence of inflammatory bowel disease among young men in Korea between 2003 and 2008. Dig Dis Sci 56: 1154-1159, 2011.

2. Cucchiara S and Stronati L: Incidence in pediatric IBD is rising: Help from health administrative data. Inflamm Bowel Dis 17: 1048-1049, 2011.

3. Rufo PA and Bousvaros A: Challenges and progress in pediatric inflammatory bowel disease. Curr Opin Gastroenterol 23: 406-412, 2007.

4. Hugot JP and Bellaiche M: Inflammatory bowel diseases: The paediatric gastroenterologist's perspective. Pediatr Radiol 37: 1065-1070, 2007.

5. Yamamoto H, Sekine Y, Sato Y, Higashizawa T, Miyata T, Iino S, Ido K and Sugano K: Total enteroscopy with a nonsurgical steerable double-balloon method. Gastrointest Endosc 53: 216-220, 2001.

6. Di Nardo G, de Ridder L, Oliva S, Casciani E, Escher JC and Cucchiara S: Enteroscopy in paediatric Crohn's disease. Dig Liver Dis 45: 351-355, 2013.

7. Levine JS and Burakoff R: Extraintestinal manifestations of inflammatory bowel disease. Gastroenterol Hepatol (N Y) 7: 235-241, 2011

8. Sands BE, Tremaine WJ, Sandborn WJ, Rutgeerts PJ, Hanauer SB, Mayer L, Targan SR and Podolsky DK: Infliximab in the treatment of severe, steroid-refractory ulcerative colitis: A pilot study. Inflamm Bowel Dis 7: 83-88, 2001.

9. Danese S, Colombel JF, Reinisch W and Rutgeerts P: Review article: Infliximab for Crohn's disease treatment-shifting therapeutic strategies after 10 years of clinical experience. Aliment Pharmacol Ther 33: 857-869, 2011.

10. Järnerot G, Hertervig E, Friis-Liby I, Blomquist L, Karlén P, Grännö C, Vilien M, Ström M, Danielsson A, Verbaan H, et al: Infliximab as rescue therapy in severe to moderately severe ulcerative colitis: A randomized, placebo-controlled study. Gastroenterology 128: 1805-1811, 2005.

11. Dredge K, Marriott JB, Macdonald CD, Man HW, Chen R, Muller GW, Stirling D and Dalgleish AG: Novel thalidomide analogues display anti-angiogenic activity independently of immunomodulatory effects. Br J Cancer 87: 1166-1172, 2002. 
12. Lentzsch S, LeBlanc R, Podar K, Davies F, Lin B, Hideshima T, Catley L, Stirling DI and Anderson KC: Immunomodulatory analogs of thalidomide inhibit growth of Hs Sultan cells and angiogenesis in vivo. Leukemia 17: 41-44, 2003.

13. Zheng CF, Xu JH, Huang Y and Leung YK: Treatment of pediatric refractory Crohn's disease with thalidomide. World J Gastroenterol 17: 1286-1291, 2011.

14. Wang XQ, Zhang Y, Xu CD, Jiang LR, Huang Y, Du HM and Wang XJ: Inflammatory bowel disease in Chinese children: A multicenter analysis over a decade from Shanghai. Inflamm Bowel Dis 19: 423-428, 2013.

15. Society of Pediatrics of China, Digestology group: Consensus on diagnostic criteria of pediatric inflammatory bowel disease. Chinese J Practical Pediatr 25: 263-265, 2010 (In Chinese).

16. Hyams JS, Ferry GD, Mandel FS, Gryboski JD, Kibort PM, Kirschner BS, Griffiths AM, Katz AJ, Grand RJ, Boyle JT, et al: Development and validation of a pediatric Crohn's disease activity index. J Pediatr Gastroenterol Nutr 12: 439-447, 1991.

17. Vermeire S, Van Assche G and Rutgeerts P: Laboratory markers in IBD: Useful, magic, or unnecessary toys? Gut 55: 426-431, 2006.

18. Pozler O, Maly J, Bonova O, Dedek P, Frühauf P, Havlickova A, Janatova T, Jimramovsky F, Klimova L, Klusacek D, et al: Incidence of Crohn disease in the Czech Republic in the years 1990 to 2001 and assessment of pediatric population with inflammatory bowel disease. J Pediatr Gastroenterol Nutr 42: 186-189, 2006

19. Heyman MB, Kirschner BS, Gold BD, Ferry G, Baldassano R, Cohen SA, Winter HS, Fain P, King C, Smith $T$ and El-Serag HB: Children with early-onset inflammatory bowe disease (IBD): Analysis of a pediatric IBD consortium registry. J Pediatr 146: 35-40, 2005.

20. Prideaux L, Kamm MA, De Cruz PP, Chan FK and Ng SC: Inflammatory bowel disease in Asia: A systematic review. J Gastroenterol Hepatol 27: 1266-1280, 2012.

21. Auvin S, Molinié F, Gower-Rousseau C, BrazierF, Merle V, Grandbastien B, Marti R, Lerebours E, Dupas JL, Colombel JF, et al: Incidence, clinical presentation and location at diagnosis of pediatric inflammatory bowel disease: A prospective population-based study in northern France (1988-1999). J Pediatr Gastroenterol Nutr 41: 49-55, 2005.

22. IBD Working Group of the European Society for Paediatric Gastroenterology, Hepatology and Nutrition: Inflammatory bowel disease in children and adolescents: Recommendations for diagnosis-the Porto criteria. J Pediatr Gastroenterol Nutr 41: 1-7, 2005.

23. Mutalib M, Blackstock S, Evans V, Huggett B, Chadokufa S, Kiparissi F and Elawad M: Eosinophilic gastrointestinal disease and inflammatory bowel disease in children: Is it a disease continuum? Eur J Gastroenterol Hepatol 27: 20-23, 2015

24. Dodell GB, Albu JB, Attia L, McGinty J, Pi-Sunyer FX and Laferrère B: The bariatric surgery patient: Lost to follow-up; From morbid obesity to severe malnutrition. Endocr Pract 18 e21-e25, 2012.

25. Yüksel I, Ataseven H, Başar O, Köklü S, Ertuğrul I, Ulker A, Dağlı U and Saşmaz N: Peripheral arthritis in the course of inflammatory bowel diseases. Dig Dis Sci 56: 183-187, 2011.

26. Cai C, Shen J, Zhao D, Qiao Y, Xu A, Jin S, Ran Z and Zheng Q: Serological investigation of food specific immunoglobulin $G$ antibodies in patients with inflammatory bowel diseases. PLoS One 9: e112154, 2014

27. Liu S, Ren J, Xia Q, Wu X, Han G, Ren H, Yan D, Wang G, Gu G and Li J: Preliminary case-control study to evaluate diagnostic values of $\mathrm{C}$-reactive protein and erythrocyte sedimentation rate in differentiating active Crohn's disease from intestinal lymphoma, intestinal tuberculosis and Behcet's syndrome. Am J Med Sci 346: 467-472, 2013.
28. Castellaneta SP, Afzal NA, Greenberg M, Deere H, Davies S, Murch SH, Walker-Smith JA, Thomson M and Srivistrava A: Diagnostic role of upper gastrointestinal endoscopy in pediatric inflammatory bowel disease. J Pediatr Gastroenterol Nutr 39: 257-261, 2004.

29. Mamula P, Telega GW, Markowitz JE, Brown KA, Russo PA, Piccoli DA and Baldassano RN: Inflammatory bowel disease in children 5 years of age and younger. Am J Gastroenterol 97: 2005-2010, 2002

30. Lin TK and Erdman SH: Double-balloon enteroscopy: Pediatric experience. J Pediatr Gastroenterol Nutr 51: 429-432, 2010.

31. Mensink PB, Groenen MJ, Van Buuren HR, Kuipers EJ and Van der Woude CJ: Double-balloon enteroscopy in Crohn's disease patients suspected of small bowel activity: Findings and clinical impact. J Gastroenterol 44: 271-276, 2009.

32. Huang Y, Shao CH and Leung YK: Application of double balloon enteroscopy in pediatric patients. Zhonghua Er Ke Za Zhi 48: 599-602, 2010 (In Chinese).

33. Robert ME, Tang L, Hao LM and Reyes-Mugica M: Patterns of inflammation in mucosal biopsies of ulcerative colitis: Perceived differences in pediatric populations are limited to children younger than 10 years. Am J Surg Pathol 28: 183-189, 2004.

34. Washington K, Greenson JK, Montgomery E, Shyr Y, Crissinger KD, Polk DB, Barnard J and Lauwers GY: Histopathology of ulcerative colitis in initial rectal biopsy in children. Am J Surg Pathol 26: 1441-1449, 2002.

35. Pierik M, De Hertogh G, Vermeire S, Van Assche G, Van Eyken P, Joossens S, Claessens G, Vlietinck R, Rutgeerts P and Geboes K: Epithelioid granulomas, pattern recognition receptors, and phenotypes of Crohn's disease. Gut 54: 223-227, 2005

36. Tiemi J, Komati S and Sdepanian VL: Effectiveness of infliximab in Brazilian children and adolescents with Crohn disease and ulcerative colitis according to clinical manifestations, activity indices of inflammatory bowel disease, and corticosteroid use. J Pediatr Gastroenterol Nutr 50: 628-633, 2010.

37. Hyams JS, Lerer T, Griffiths A, Pfefferkorn M, Stephens M, Evans J, Otley A, Carvalho R, Mack D, Bousvaros A, et al; Pediatric Inflammatory Bowel Disease Collaborative Research Group: Outcome following infliximab therapy in children with ulcerative colitis. Am J Gastroenterol 105: 1430-1436, 2010.

38. Oldenburg B and Hommes D: Biological therapies in inflammatory bowel disease: Top-down or bottom-up? Curr Opin Gastroenterol 23: 395-399, 2007.

39. Facchini S, Candusso M, Martelossi S, Liubich M, Panfili E and Ventura A: Efficacy of long-term treatment with thalidomide in children and young adults with Crohn disease: Preliminary results. J Pediatr Gastroenterol Nutr 32: 178-181, 2001.

40. Lazzerini M, Martelossi S, Marchetti F, Scabar A, Bradaschia F, Ronfani L and Ventura A: Efficacy and safety of thalidomide in children and young adults with intractable inflammatory bowel disease: Long-term results. Aliment Pharmacol Ther 25: 419-427, 2007.

41. Stefan DC, Andronikou S, Freeman N and Schoeman J: Recovery of vision after adjuvant thalidomide in a child with tuberculous meningitis and acute lymphoblastic leukemia. J Child Neurol 24: 166-169, 2009.

42. Schoeman JF, Fieggen G, Seller N, Mendelson M and Hartzenberg B: Intractable intracranial tuberculous infection responsive to thalidomide: Report of four cases. J Child Neurol 21: 301-308, 2006.

43. Priolo T, Lamba LD, Giribaldi G, De Negri E, Grosso P, De Grandis E, Veneselli E, Buoncompagni A, Viola S, Alpigiani MG, et al: Childhood thalidomide neuropathy: A clinical and neurophysiologic study. Pediatr Neurol 38: 196-199, 2008. 